\title{
Halloysite silanization in polyethylene terephthalate composites for bottling and packaging applications
}

\author{
Fernando Garcia-Escobar ${ }^{1}$ (1), Jaime Bonilla-Rios ${ }^{1, *}$ (D), Adriana Berenice Espinoza-Martinez ${ }^{2}$ (D), and \\ Patricia Cerda-Hurtado ${ }^{3}$ (I) \\ 'Escuela de Ingeniería y Ciencias, Tecnológico de Monterrey, Ave. Eugenio Garza Sada 2501 Sur, 64849 Monterrey, Nuevo León, \\ Mexico \\ ${ }^{2}$ Departamento de Procesos de Transformación, Centro de Investigación en Química Aplicada, Blvd. Enrique Reyna 140, \\ 25253 Saltillo, Coahuila, Mexico \\ ${ }^{3}$ Centro de Investigación en Materiales Avanzados, S. C., Parque de Investigación e Innovación Tecnológica, Unidad Monterrey, \\ Alianza 6 Norte 202, 66628 Apodaca, Nuevo León, Mexico
}

Received: 17 March 2021

Accepted: 10 July 2021

Published online:

4 August 2021

(C) The Author(s) 2021

\begin{abstract}
Composite materials of polyethylene terephthalate with silanized halloysite nanoclay were prepared and characterized. Halloysite was first functionalized with benzoyloxypropyltrimethoxysilane and then incorporated it into the polymer matrix via melt extrusion at $0.5,1$, and $2 \mathrm{wt} \%$ clay load ratios. The modified clay was characterized by means of elemental carbon quantification, thermogravimetric analysis, X-ray diffraction, and nitrogen adsorption-desorption. The silanization was confirmed to have taken place with an approximate reaction yield of $5 \%$. While the silanization did not significantly affect the crystal structure or the morphological properties of the clay, a mass loss starting from $190{ }^{\circ} \mathrm{C}$ attributed to the organosilane compound used to modify the clay was observed in the reacted samples, along with increased thermal stability. The composite materials exhibited an increase in Young's modulus and a decrease in the ultimate strain, but not a significant change in the oxygen permeability of the composites with respect to the neat PET.
\end{abstract}

Handling Editor: Dale Huber.

Address correspondence to E-mail: jbonilla@tec.mx 


\section{GRAPHICAL ABSTRACT}

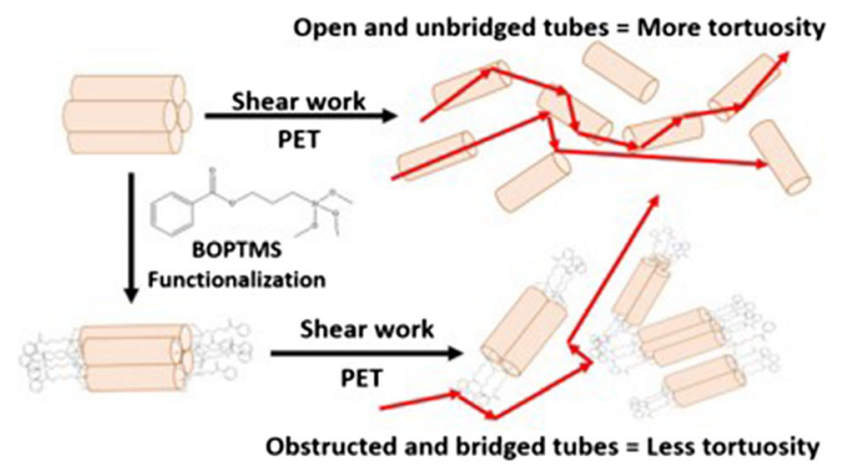

\section{Introduction}

The development of polymeric composite materials with lower gas permeability than the matrix has garnered attention in recent years, as a lower gas permeability can increase the shelf life of food products by delaying the inward diffusion of oxygen that can spoil the freshness of the contained product or the outward diffusion of $\mathrm{CO}_{2}$ in carbonated beverages. Polyethylene terephthalate (PET), a polyester resin possessing good tensile strength, impact strength, optical clarity, and thermal stability, is the most widely used material in bottling liquid products for human consumption. In particular, clay minerals have been studied as filler candidates in polymer composites to reinforce the mechanical properties of the material and reduce permeability for packaging applications [1-3].

The use of clay minerals as fillers, such as halloysite (HNT) and montmorillonite (MMT), has attracted interest due to their natural origin and low cost $[4,5]$. Halloysite is an aluminosilicate clay mineral with the formula $\mathrm{Al}_{2} \mathrm{Si}_{2} \mathrm{O}_{5}(\mathrm{OH})_{4} \cdot n \mathrm{H}_{2} \mathrm{O}$ consisting of a double layer of tetrahedral silicon oxide on the outside and octahedral aluminum oxide on the inside, rolled up into a hollow tubular shape. The chemical modification of halloysite with an organosilane coupling agent with specific functional groups can lead to better dispersion of the clay in the polymer matrix [6, 7]. Variables such as the chemical structure of the organosilane, or the reaction conditions of the functionalization reaction, can affect the way the organosilane attaches to the nanotubes, and consequently, the way the modified clay interacts with the matrix $[8,9]$.

These interactions are especially important since an improved dispersion of the filler in the polymer might lead to a reduced gas permeability of the material by increasing the tortuous path, the gas molecules of the diffusing substances must overcome to pass through the matrix [10-14]. However, low matrix-filler compatibility and the sensitivity of PET to degradation due to humidity, high temperature, and shear stresses during melt processing are aspects that must be considered to create a viable PET composite material $[15,16]$.

Studies on improving the barrier properties of PET have been conducted employing composites containing neat and chemically modified montmorillonite clays [17]. The results share a trend where composites containing MMT clay modified with organic salts are better than neat MMT due to a better dispersion of the clay layers throughout the material $[18,19]$. An additional modification of the clay material with oleic acid further enhanced the gas barrier properties of the final composite due to an even better dispersion of the clay in the matrix and to the carboxylic acid serving as a scavenger for oxygen molecules diffusing through the material [20].

Halloysite clay can serve as a cheaper alternative to montmorillonite in polymer/clay composites [5]. To the best of our knowledge, the only work on PET/ HNT composites was reported by Gorrasi et al. [21] 
who studied these materials intended for bottling applications and concluded that although the incorporation of the clay in the PET matrix reinforces the mechanical properties of the material, the agglomerated clay particles act as nucleation centers when the material is cooled after melt compounding, making the material overall prone to crystallization and to be brittle and opaque: properties not desirable in bottles.

To address this area of opportunity, we studied the silanization of halloysite nanoclay with benzoyloxypropyltrimethoxysilane (BOPTMS) to improve the clay's compatibility with the polymer matrix and its dispersion in the material. The enhanced dispersion will, in turn, enhance the gas barrier properties of the composite without compromising the material's mechanical properties and optical clarity. The decrease in the barrier properties could be attributed to an increase in the tortuosity of the gas going through the matrix as well as through the nanoparticle that could be interpreted as the nanotube capacity to absorb gas [22].

\section{Methodology}

\section{Materials}

Halloysite nanoclay with a surface area of approximately $50 \mathrm{~m}^{2} / \mathrm{g}$ and ethanol (99.97\%) were purchased from Sigma-Aldrich (México). Benzoyloxypropyltrimethoxysilane (BOPTMS, 99\%) was purchased from Gelest, Inc. (North Carolina, United States). Toluene (99.94\%) was purchased from CTR Scientific (Monterrey, México). Bottle-grade polyethylene terephthalate resin (PET, Cleartuf 8006) with an intrinsic viscosity of $0.8 \mathrm{dL} / \mathrm{g}$ was supplied by Contenedores IEM, S.A. de C.V. (Monterrey, México). All materials were used without further purification.

\section{Halloysite functionalization}

In a typical halloysite functionalization procedure, $2 \mathrm{~g}$ of clay was dried at $200{ }^{\circ} \mathrm{C}$ for $12 \mathrm{~h}$ before the reaction. Once dry, the clay was suspended in $15 \mathrm{~mL}$ of dry solvent (toluene or acetone) and ultrasonically dispersed for $30 \mathrm{~min}$ under a dry atmosphere to reduce particle size. The system was then heated at half of the solvent's boiling temperature, and $2.1 \mathrm{~mL}$ of BOPTMS was dissolved in $10 \mathrm{~mL}$ of solvent and added into the reaction system dropwise under constant stirring. The mixture was then refluxed for $12 \mathrm{~h}$ with continuous stirring under a dry atmosphere at $119{ }^{\circ} \mathrm{C}$ for toluene and $56^{\circ} \mathrm{C}$ for acetone. The modified clay was then thoroughly washed with dried toluene and ethanol to remove any present unreacted organosilane. Finally, the product was cured at $120{ }^{\circ} \mathrm{C}$ for $12 \mathrm{~h}$, collected and preserved in a dry atmosphere. A schematic representation of the reaction can be found in Fig. 1. The nomenclature used for the studied functionalized halloysite samples was established as HNT_200_X, where X stands for the reaction solvent ( $\mathrm{A}$ for acetone and $\mathrm{T}$ for toluene). HNT stands for a blank halloysite sample that was not dried or reacted, and HNT_200 represents a clay sample that was dried, but not reacted with the organosilane.

\section{PET/HNT composite preparation}

Previous to processing, the materials were dried at $70{ }^{\circ} \mathrm{C}$ under vacuum for $24 \mathrm{~h}$ to remove water that may promote polymer degradation during processing. The composites were prepared by loading the polymer at $0.5,1$, and $2 \mathrm{wt} \%$ with halloysite clay and extruding the materials with an Intelli Plasti-Corder Brabender Torque Rheometer coupled to a three-zone twin-screw extruder at temperatures of $270{ }^{\circ} \mathrm{C}$ for zones I and II and $265^{\circ} \mathrm{C}$ for zone III and a screw speed of $50 \mathrm{rpm}$ with an average residence time of $70 \mathrm{~s}$.

The 1-mm-thick samples used for the oxygen permeation and mechanical characterization were injected after the extrusion with a Nissei FNX80 machine at an injection speed of $55 \mathrm{~mm} \times \mathrm{s}^{-1}$, an injection time of $9 \mathrm{~s}$, a holding pressure of $58.8 \mathrm{MPa}$, screw speed of $80 \mathrm{rpm}$, mold pressure of $0.8 \mathrm{MPa}$, and a cooling time of $20 \mathrm{~s}$. Heating was divided into four zones kept at temperatures of $260,270,280$, and $290^{\circ} \mathrm{C}$, the nozzle at $290{ }^{\circ} \mathrm{C}$, and the mold at $10{ }^{\circ} \mathrm{C}$.

\section{Elemental carbon analysis}

The quantification of elemental carbon on functionalized samples was carried out on a Thermo Scientific Flash2000 Organic Elemental Analyzer. The amount of elemental carbon was used to determine the grafted BOPTMS, and this, in turn, was used to estimate the reaction yield. Therefore, for each BOPTMS molecule $\left(284.38 \mathrm{~g} \times \mathrm{mol}^{-1}\right)$, the number of carbon

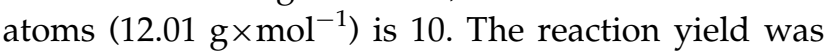




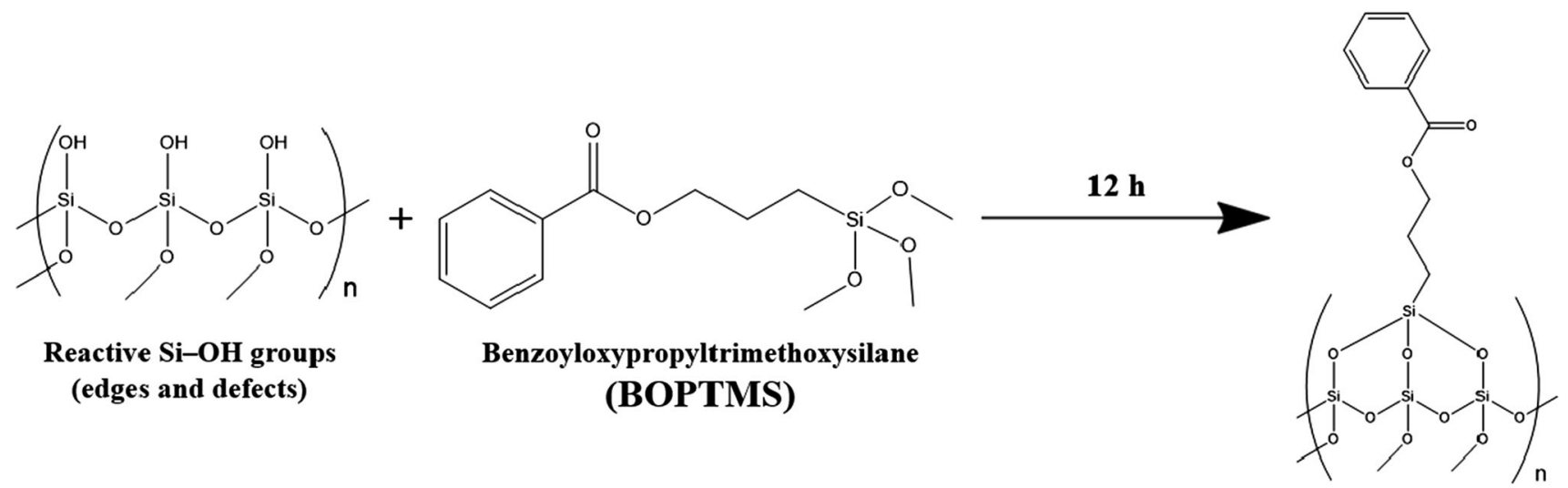

Grafted BOPTMS

Figure 1 Grafting of BOPTMS on reactive silanol groups.

calculated using the grafted BOPTMS on the samples and compared to the BOPTMS $\left(1.104 \mathrm{~g} \times \mathrm{cm}^{-3}\right)$ initially added.

\section{X-ray diffraction (XRD)}

X-ray diffraction was carried out on a Rigaku Miniflex 600 Powder X-ray diffractometer. The measurements were carried out with a source voltage of $30 \mathrm{kV}$ and $15 \mathrm{~mA}$ using a $\mathrm{Cu}$ cathode $(\mathrm{K} \alpha)$ as the source at a wavelength of $1.54 \AA$. The diffraction patterns were measured from 3 to $60^{\circ}$ with a step of 0.05 and a scanning rate of $2 \times \mathrm{min}^{-1}$. No specific sample preparation was required.

\section{Thermogravimetric analyses (TGA)}

Thermogravimetric analyses were carried out on a TA Instruments Thermal Analysis Q500 instrument. The samples were heated from 30 to $800{ }^{\circ} \mathrm{C}$ at a heating rate of $10{ }^{\circ} \mathrm{C} \times \mathrm{min}^{-1}$. A nitrogen atmosphere was used when heating the samples from 30 to $600{ }^{\circ} \mathrm{C}$, and an oxygen atmosphere was used from $600{ }^{\circ} \mathrm{C}$ onwards.

\section{Nitrogen adsorption-desorption}

Nitrogen adsorption-desorption was carried out on a Quantachrome Novatouch NT1LX-1 instrument. Specific surface areas were calculated with the Brunauer-Emmett-Teller (BET) method, and total pore volume and pore size distributions were calculated with the Barrett-Joyner-Halenda (BJH) method. The samples were degassed under $25 \mathrm{mTorr}$ with heating at $10{ }^{\circ} \mathrm{C} \times \mathrm{min}^{-1}$ from room temperature to $60{ }^{\circ} \mathrm{C}$, held at this temperature for $1 \mathrm{~h}$, then heated at $5{ }^{\circ} \mathrm{C} \times \min ^{-1}$ to $110^{\circ} \mathrm{C}$, and held at this temperature for $4 \mathrm{~h}$.

\section{Composite mechanical properties}

The mechanical behavior of the composites was studied with an Instron 3365 uniaxial testing machine on type $\mathrm{V}$ bone-shaped specimens. The samples were tested at a deformation rate of $10 \mathrm{~mm} / \mathrm{min}$ at an initial clamp separation of $12.7 \mathrm{~mm}$ at $25{ }^{\circ} \mathrm{C}$.

\section{Oxygen permeability}

Oxygen permeability of the composites was studied with a Mocon Ox-Tran 2/61 tester. The exposed area of the samples was $10 \mathrm{~cm}^{2}$, and the thickness of the samples ranged from 0.8 to $1 \mathrm{~mm}$. A mixture of $98 \%$ $\mathrm{N}_{2}$ and $2 \% \mathrm{H}_{2}$ was used as a carrier gas. The instrument was calibrated with a standard Mylar polyester film before sample measurements.

Table 1 Results of elemental carbon analysis data of dried and functionalized halloysite samples

\begin{tabular}{llll}
\hline Sample & \multicolumn{2}{l}{ Elemental C (\%) } & \multirow{2}{*}{ Rxn. yield (\%) } \\
\cline { 2 - 3 } & Neat & Treated & \\
\hline HNT_200 (Blank) & Not detected & - \\
HNT_200_T & $1.99 \pm 0.12$ & $2.50 \pm 0.75$ & $4.07 \pm 0.26$ \\
HNT_200_A & $2.72 \pm 0.42$ & $2.61 \pm 0.34$ & $5.56 \pm 0.86$ \\
\hline
\end{tabular}




\section{Results}

\section{Elemental carbon analysis}

The results on elemental carbon quantification, as well as the calculated BOPTMS functionalization reaction efficiency data, are reported in Table 1. Two types of functionalized samples were studied: the samples straight from the functionalization reactions (neat) and samples treated afterward at $280{ }^{\circ} \mathrm{C}$ for $5 \mathrm{~min}$ to simulate the processing conditions of PET.

\section{Thermogravimetric analysis}

The results are shown in Fig. 2. In neat halloysite, a small mass loss was observed at around $130{ }^{\circ} \mathrm{C}$, likely pertaining to weakly bound water on the surface, along with a considerable weight loss $\left(\Delta \mathrm{M}_{\mathrm{D}}\right)$ starting at around $330{ }^{\circ} \mathrm{C}$ corresponding to the dihydroxylation of the nanotubes [21]. Two mass losses are observed in dried halloysite: the first starting at $210{ }^{\circ} \mathrm{C}$, likely corresponding to crystallization water present in the sample, and the second one $\left(\Delta M_{D}\right)$ corresponding to dehydroxylation starting around $330{ }^{\circ} \mathrm{C}$. In functionalized samples, a mass loss $\left(\Delta M_{\mathrm{o}}\right)$ starting at $\left(T_{1}\right)$ and continuing until sample dihydroxylation $\left(T_{2}, \Delta M_{\mathrm{D}}\right)$ was observed, which presumably corresponds to the decomposition of the organic material [23, 24].

The quantitative TGA results are reported in Table 2, where it can be observed that the organic component of the functionalized clays began to decompose at roughly the same temperature for both samples.

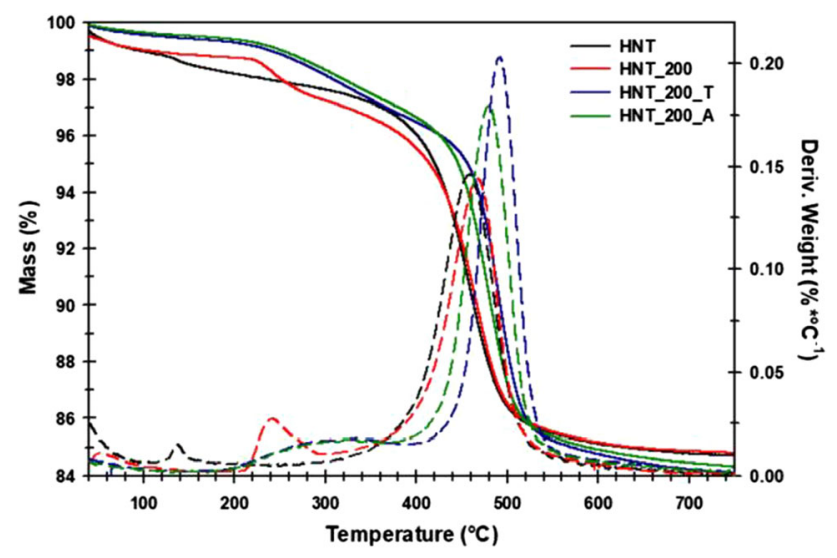

Figure 2 TGA and differential mass curves of dried and functionalized halloysite samples.
Table 2 Quantitative TGA results summary for neat and functionalized halloysite samples

\begin{tabular}{lllll}
\hline Sample & $T_{1}\left({ }^{\circ} \mathrm{C}\right)$ & $\Delta M_{\mathrm{O}}(\%)$ & $T_{2}\left({ }^{\circ} \mathrm{C}\right)$ & $\Delta M_{\mathrm{D}}(\%)$ \\
\hline HNT_200 & 212 & 1.55 & 330 & 11.10 \\
HNT_200_T & 190 & 3.16 & 412 & 11.14 \\
HNT_200_A & 192 & 2.48 & 387 & 11.40 \\
\hline
\end{tabular}

\section{X-ray diffraction}

The diffraction patterns of the studied samples are reported in Fig. 3. The diffraction pattern of the neat clay reveals the presence of quartz impurities in the sample, as reported similarly by Yuan et al. [23] and Joussein et al. [25].

The comparison for the spacings in the clay is presented in Table 3 . The space between the $\left(\begin{array}{lll}0 & 0 & 1\end{array}\right)$ planes is reduced by $0.02 \mathrm{~nm}$ after drying the samples, and returns to $0.72 \mathrm{~nm}$ after the silanization.

\section{Nitrogen adsorption-desorption}

The nitrogen adsorption-desorption isotherms of neat halloysite and silanized samples are depicted in Fig. 4. The isotherms were of type IV with H3 hysteresis loops, corresponding to mesoporous materials [26-28]. The calculated values for surface area and pore volume and pore size are reported in Table 4.

\section{Mechanical properties}

The results of the mechanical tests of the composites are depicted in Fig. 5.

\section{Oxygen permeability}

The oxygen transmission rate (OTR) at $150 \mathrm{~h}$ is reported in Table 5 . The average permeability of the composite containing functionalized halloysite is almost the same than that of neat PET, meaning that the presence of the functionalized filler has a minimal effect on this property at $0.5 \%$ load.

The barrier effect behavior of the materials is depicted on Fig. 6, where no significant difference was observed between the different types of samples. The composite containing non-functionalized halloysite, however, displayed a lower oxygen permeability than the functionalized one. 

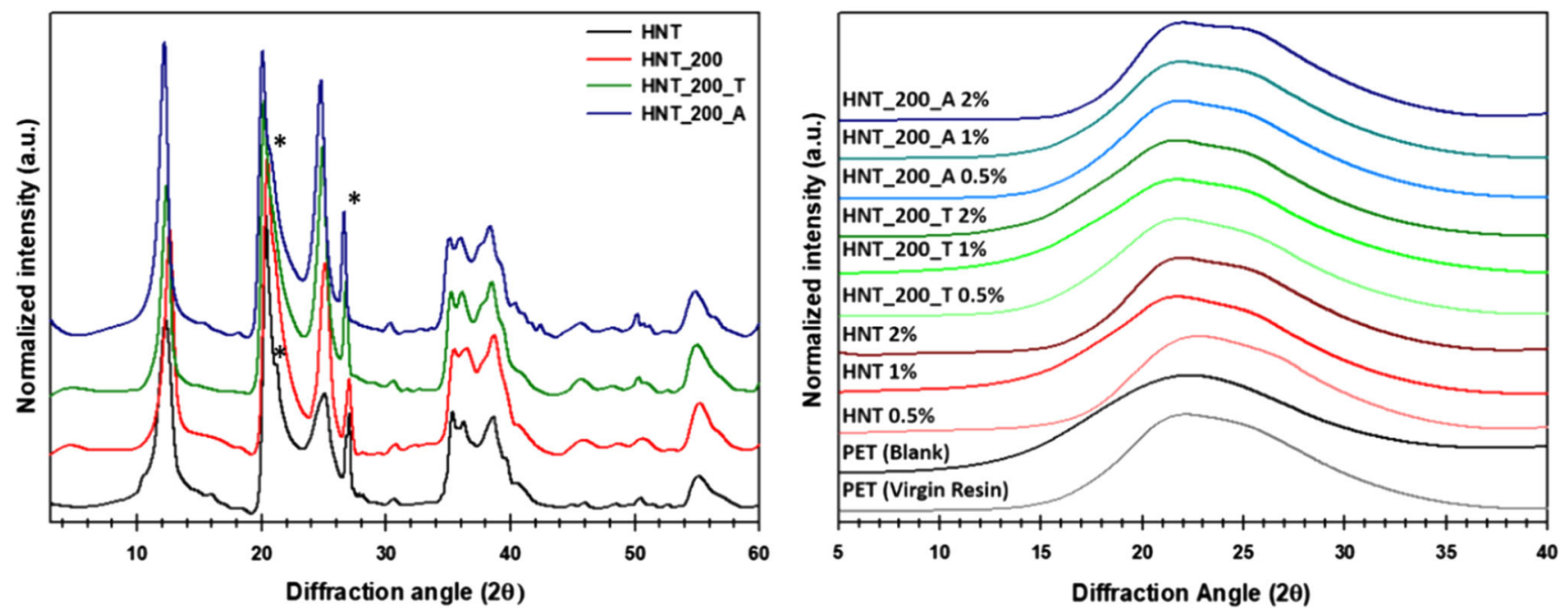

Figure 3 Diffraction patterns of neat, dried, and functionalized halloysite samples (left) and of the PET/HNT composite materials (right). Peaks pertaining to quartz impurities are highlighted with an *.

Table 3 Spacings for the $\left(\begin{array}{ll}0 & 0\end{array}\right.$ 1) plane for neat, dried, and functionalized halloysite samples

\begin{tabular}{ll}
\hline Sample & $d_{001}(\mathrm{~nm})$ \\
\hline HNT & 0.72 \\
HNT_200 & 0.70 \\
HNT_200_T & 0.72 \\
HNT_200_A & 0.72 \\
\hline
\end{tabular}

\section{Discussion}

\section{Halloysite functionalization}

The carbon elemental analysis results indicate that heating the sample at $280{ }^{\circ} \mathrm{C}$ for $5 \mathrm{~min}$ does not appear to reduce the carbon content significantly, meaning the organic components of the functionalizing agents do not decompose rapidly enough if processed under a similar residence time. It is also apparent that silanizing the clay in acetone yields a higher amount of organic material in the clay. This can be explained through the mechanism in which the organosilane reacts with the different species in the medium. Yuan et al. [23] explained that there are two competing processes: grafting and oligomerization of BOPTMS. Carli et al. [9] also reported that when HNT modification with organosilanes occurred in ethanol, this led to the formation of an oligomerized structure being favored. The polar nature of acetone and the presence of trace amounts of water in
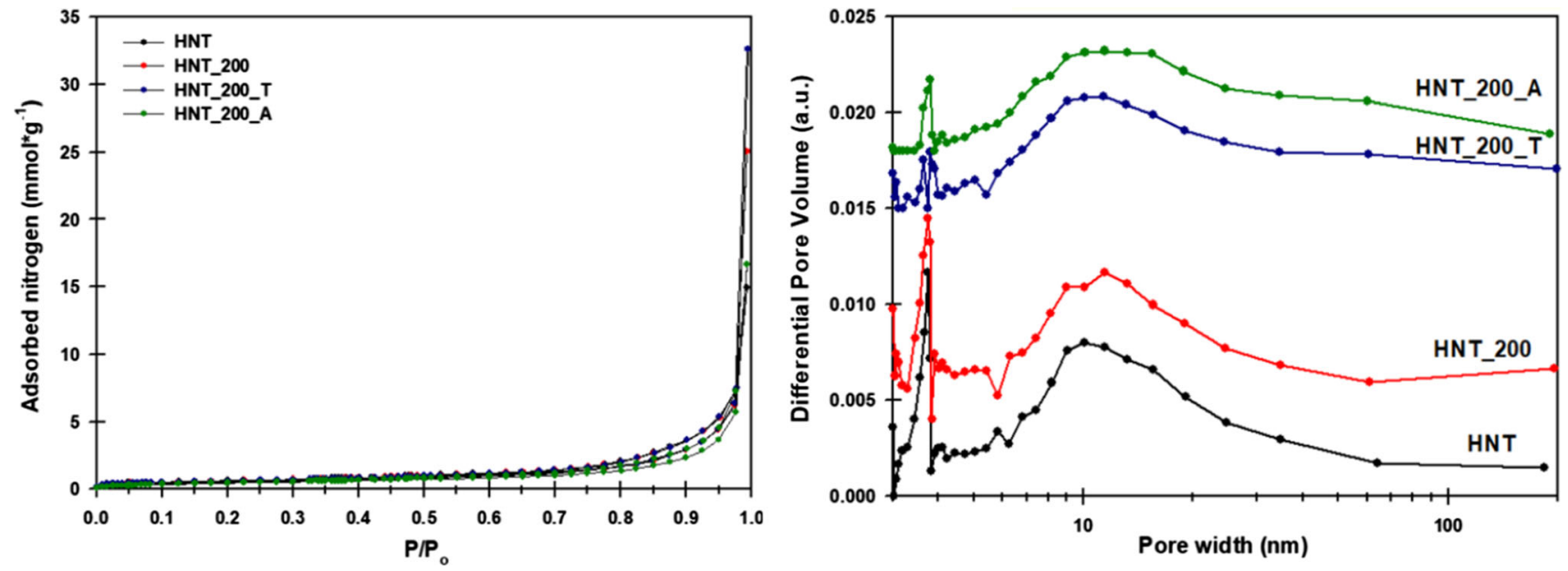

Figure 4 Nitrogen adsorption-desorption isotherms of neat, dried, and functionalized halloysite samples (left) and pore size distribution curves of the samples (right). 
Table 4 Specific surface area (S) and pore data extracted from the nitrogen adsorption-desorption isotherms of neat, dried, and functionalized halloysite samples

\begin{tabular}{lll}
\hline Sample & $\mathrm{S}\left(\mathrm{m}^{2} \times \mathrm{g}^{-1}\right)$ & Pore volume $\left(\mathrm{cm}^{3} \times \mathrm{g}^{-1}\right)$ \\
\hline HNT & $50.7 \pm 0.16$ & $0.5 \pm 0.01$ \\
HNT_200 & $49.2 \pm 1.43$ & $0.9 \pm 0.01$ \\
HNT_200_T & $39.5 \pm 0.86$ & $0.7 \pm 0.11$ \\
HNT_200_A & $33.2 \pm 0.89$ & $0.5 \pm 0.06$ \\
\hline
\end{tabular}

the solvent can explain the observed results: the organosilane reacted in acetone could have been hydrolyzed readily and then been grafted on the HNTs or oligomerized, with oligomerization being more likely as previous results suggest. Although the difference is less than $2 \%$ in reaction yield, this can
Table 5 Oxygen transmission results of PET/HNT composites of non-modified and functionalized halloysite samples

\begin{tabular}{ll}
\hline Sample & OTR $\left(\mathrm{cc} \times \mathrm{m}^{-2} \times \mathrm{d}^{-1}\right)$ \\
\hline PET & $2.52 \pm 0.16$ \\
HNT 0.5\% & $2.34 \pm 0.17$ \\
HNT_200_A $0.5 \%$ & $2.64 \pm 0.17$ \\
\hline
\end{tabular}

lead to a cheaper approach to functionalize the clay in terms of the energy required to reflux the mixture, since the boiling point of acetone is approximately half the boiling point of toluene.

Based on the appearance of the mass differential curves, the thermal decomposition of the organic material is a gradual process that does not conclude upon reaching the temperature where

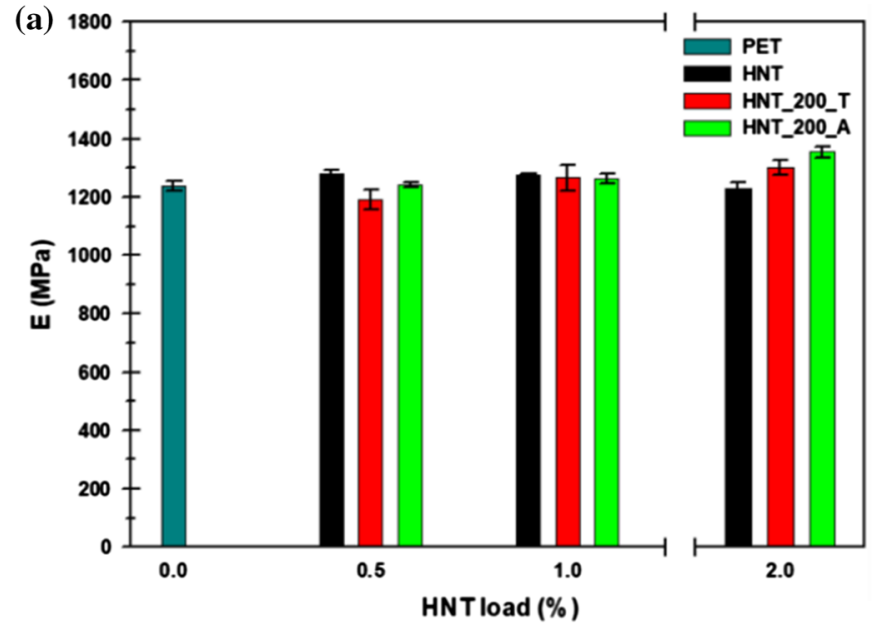

(b)

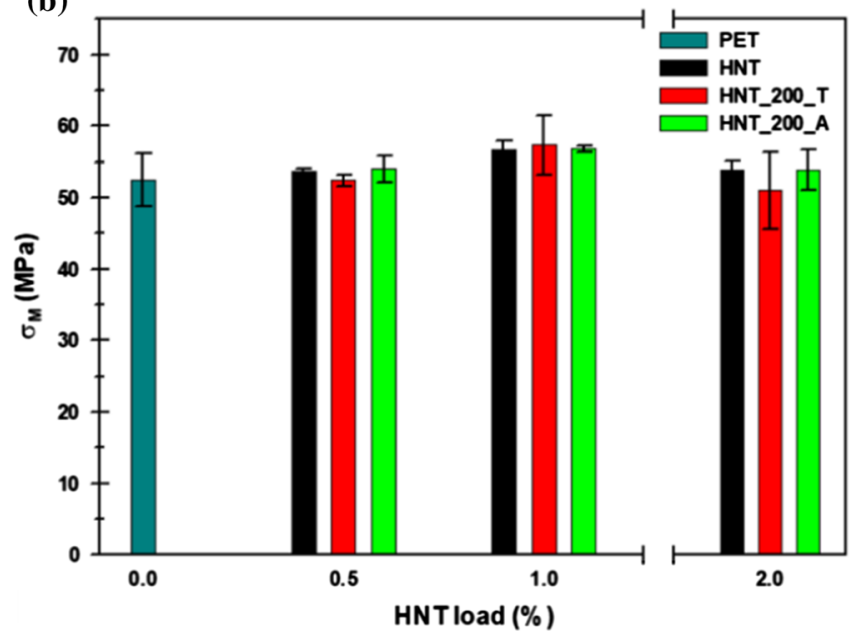

(c)

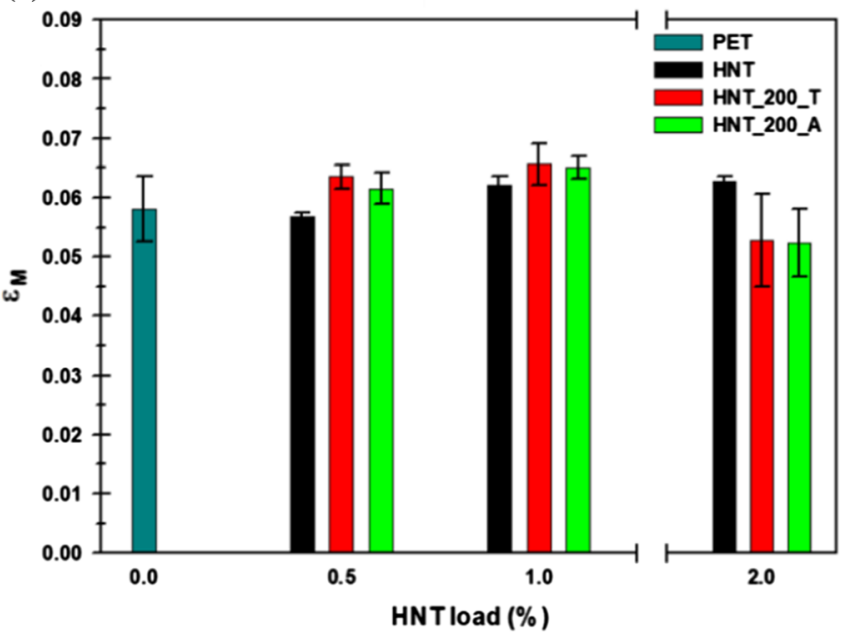

Figure 5 Young's modulus (a), maximum load (b) and strain at maximum load (c) of the PET/HNT composites at different clay loads. 


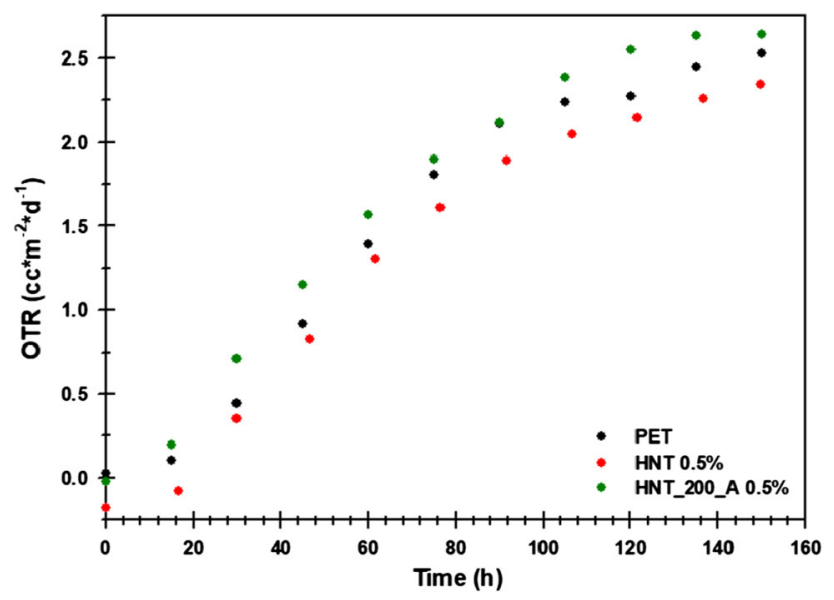

Figure 6 Average oxygen transmission rate of PET and composite samples at $0.5 \%$ filler load.

dehydroxylation starts, meaning that both processes overlap for the studied samples. Interestingly, it was observed that the dehydroxylation of the functionalized samples starts at higher temperatures when compared to the clay that was only dried. The greater effect, observed for sample HNT_200_T, has the thermal stability of the clay increased for $80{ }^{\circ} \mathrm{C}$. This is surprising, considering that on previously reported results of functionalized halloysite, the functionalized clay starts to dehydroxylate at lower temperatures than neat halloysite [8, 9, 24]. Wang and Huang previously commented on the effect HNTs have on the thermal decomposition of polymer composites, in which the nanotubes help contain and delay the release of volatile species that are generated during thermal degradation, increasing the thermal stability of the composites. The substitution of the clay's hydroxyl groups through grafting of the organosilane also helps increase the stability of PET composites, since the release of these hydroxyl groups may lead to hydrolytic decomposition of the polymer [21, 29].

The crystal structure of the clay was not significantly affected by the drying nor the silanization reaction. This change in the basal spacing may be attributed to the functionalization reaction [30], but is not significant enough to allow organosilane grafting between the rolled layers of a halloysite nanotube [23]. These results may indicate that the grafting and silane oligomerization takes place on the available silanol groups available on the outer edges of the tube and the available aluminol groups on the edges and the lumen $[8,9,23,24]$.
The surface area did not change significantly from roughly $50 \mathrm{~m}^{2} \times \mathrm{g}^{-1}$ after drying the clay before silanizing it. However, it decreased to under 40 $\mathrm{m}^{2} \times \mathrm{g}^{-1}$ in both reacted samples due to the condensed and deposited silane reducing the surface area. The pore volume grew after drying the clay but was once again reduced after the reaction, perhaps due to the organosilane molecules occupying the space inside the pores and blocking the edges of the nanotubes, as described by Tan et al. [31]. Two main pore size populations were observed: one around $2.6 \mathrm{~nm}$ corresponding to slit-shaped mesopores corresponding to the layers of the rolled nanotube that separate and form slit-like pores upon dehydration as reported by Kohyama et al. [32], and a broad distribution centered around $10 \mathrm{~nm}$ corresponding to the lumen of the nanotubes. The pore size distribution was not significantly altered after drying the clay at the reported temperatures, which is consistent with the results reported by Yuan et al. [27]. However, the differential pore volume is notably lower in the functionalized samples due to the organosilane molecules reacting with the $-\mathrm{OH}$ groups located in the outer edges of the nanotubes and covering them, leaving the lumen as the most abundant pores.

\section{Halloysite composite mechanical properties}

The injected composite samples had a good optical clarity indicative of amorphous samples, as observed on Fig. 7. Although the effect of the clay on Young's modulus of the composite is not significantly different to that of neat PET, it can be observed that the composite at $2 \%$ load has a higher Young's modulus, a lower ultimate strength $\left(\sigma_{\mathrm{M}}\right)$, and specially a lower ultimate strain $\left(\varepsilon_{\mathrm{M}}\right)$. Based on these two parameters, it can be said that the composite containing the clay functionalized in toluene has the lowest resilience $\left(\sigma_{\mathrm{M}} \varepsilon_{\mathrm{M}}\right)$ and that a concentration percolation threshold should be between 1 and $2 \%$. Based on this observation, the best silanized sample would be the one functionalized in acetone at a filler load lower than $2 \%$ to prevent an alteration of the mechanical properties.

\section{Halloysite composite gas permeability}

The composite samples display the same tendency as neat PET. The observed behavior on Fig. 6 may be indicative that there is a slightly lower permeability 


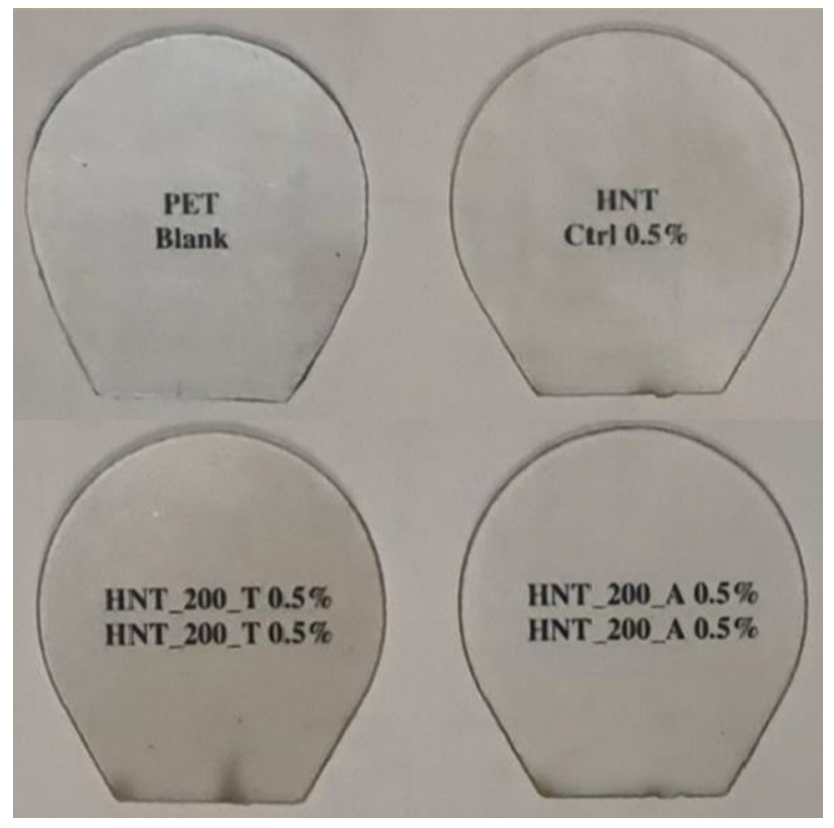

Figure 7 PET and composite samples used in oxygen permeability tests on top of a paper sheet with printed sample labels.

on non-functionalized composite samples when compared to the functionalized ones. This can be due to the functionalized composites containing halloysite nanotubes with obstructed edges and pores, making gas diffusion inside the tubes difficult and reducing the overall tortuosity of the system. The oligomerization of some organosilane moieties could have also bridged some nanotubes, further blocking gas molecules from diffusing into the tubes. Nonfunctionalized clay nanotubes, on the other hand, are not chemically bridged and can be separated with the shear work during the composite processing. However, the composite containing functionalized clay has, statistically speaking, the same permeability as if it were no filler was present. This indicates that a deeper study on the dispersion of the functionalized composites is needed.

\section{Conclusions}

Halloysite clay was functionalized with BOPTMS, and PET composites were prepared at clay loadings of $0.5,1$, and $2 \%$ with the objective to improve the gas barrier properties of the material while conserving the same mechanical properties of the neat polymer. The presence of deposited organic material on the clay was assessed by quantifying the organic carbon present in the functionalized samples and TGA. The mass loss at temperatures higher than $190{ }^{\circ} \mathrm{C}$ confirmed the presence of organic material within the functionalized samples and an increased thermal stability of the clay material. The drying treatment and silanization reaction did not affect the nanoclay crystal structure significantly. Nitrogen adsorptiondesorption shed light on the way the silanizing agent deposited on the nanotubes: the porosity of the sample was reduced after silanization and the abundancy of the pores in the sample shifted from the slit-like pores between the nanotubes' layers to the lumen, indicating the organosilane molecules reacted with the hydroxyl groups located on the edges and inside the lumen of the nanotubes.

The inclusion of the clay in the PET matrix produced a slight change in the mechanical performance of the composite materials in the studied filler concentrations, and a change in the oxygen permeability of the materials was not observed.

\section{Acknowledgements}

The authors are grateful to Contenedores IEM, S.A. de C.V. for providing the polymer resin employed in this study, as well as the Centro del Agua para América Latina y el Caribe at Tecnológico de Monterrey for their support in characterizing the materials.

\section{Funding}

This work was funded by the Consejo Nacional de Ciencia y Tecnología (CONACyT) under Grant Number 450047, Application Number 291137.

\section{Declarations}

Conflict of interest The authors declare that they have no known competing financial interests or personal relationships that could have appeared to influence the work reported in this paper.

Open Access This article is licensed under a Creative Commons Attribution 4.0 International License, which permits use, sharing, adaptation, distribution and reproduction in any medium or format, as long as you give appropriate credit to the original 
author(s) and the source, provide a link to the Creative Commons licence, and indicate if changes were made. The images or other third party material in this article are included in the article's Creative Commons licence, unless indicated otherwise in a credit line to the material. If material is not included in the article's Creative Commons licence and your intended use is not permitted by statutory regulation or exceeds the permitted use, you will need to obtain permission directly from the copyright holder. To view a copy of this licence, visit http://creativecommons.org/licen ses/by/4.0/.

\section{References}

[1] Monsiváis-Barrón AJ, Bonilla-Rios J, Ramos De Valle LF, Palacios E (2013) Oxygen permeation properties of HDPElayered silicate nanocomposites. Polym Bull 70:939-951. h ttps://doi.org/10.1007/s00289-012-0897-5

[2] Jamaludin NA, Inuwa IM, Hassan A et al (2015) Mechanical and thermal properties of SEBS-g-MA compatibilized halloysite nanotubes reinforced PET/PC nanocomposites. J Appl Polym Sci 132:1-10. https://doi.org/10.1002/app. 42608

[3] Lin T, Zhu L, Chen T, Guo B (2013) Optimization of mechanical performance of compatibilized polypropylene/ poly(ethylene terephthalate) blends via selective dispersion of halloysite nanotubes in the blend. J Appl Polym Sci 129:47-56. https://doi.org/10.1002/app.38700

[4] Liu M, Jia Z, Jia D, Zhou C (2014) Recent advance in research on halloysite nanotubes-polymer nanocomposite. Prog Polym Sci 39:1498-1525. https://doi.org/10.1016/j.pr ogpolymsci.2014.04.004

[5] Vahedi V, Pasbakhsh P (2015) Polymer nanocomposites reinforced by halloysite nanotubes: a review. In: Pasbakhsh P, Churchman GJ (eds) Natural mineral nanotubes: properties and applications. Apple Academic Press, pp 141-170

[6] Pal P, Kundu MK, Malas A, Das CK (2014) Compatibilizing effect of halloysite nanotubes in polar-nonpolar hybrid system. J Appl Polym Sci. https://doi.org/10.1002/app.39587

[7] Pasbakhsh P, Ismail H, Fauzi MA, Bakar AA (2010) EPDM/modified halloysite nanocomposites. Appl Clay Sci 48:405-413. https://doi.org/10.1016/j.clay.2010.01.015

[8] Bischoff E, Daitx T, Alexandre D et al (2015) Organosilanefunctionalized halloysite for high performance halloysite / heterophasic ethylene: propylene copolymer nanocomposites. Appl Clay Sci 112-113:68-74. https://doi.org/10.1016/ j.clay.2015.04.020
[9] Carli LN, Daitx TS, Soares GV et al (2014) The effects of silane coupling agents on the properties of PHBV/halloysite nanocomposites. Appl Clay Sci 87:311-319. https://doi.org/ 10.1016/j.clay.2013.11.032

[10] Sanchez-Garcia MD, Gimenez E, Lagaron JM (2007) Novel PET nanocomposites of interest in food packaging applications and comparative barrier performance with biopolyester nanocomposites. J Plast Film Sheeting 23:133-148. https://d oi.org/10.1177/8756087907083590

[11] Mohan TP, Kanny K (2014) Mechanical and barrier properties of copolyester-nanoclay composites. J Polym Eng 34:511-520. https://doi.org/10.1515/polyeng-2013-0202

[12] Xu XF, Ghanbari A, Leelapornpisit W et al (2011) Effect of ionomer on barrier and mechanical properties of PET/ Organoclay nanocomposites prepared by melt compounding. Int Polym Process 26:444-455. https://doi.org/10.3139/217. 2477

[13] Hamzehlou S, Katbab AA (2007) Bottle-to-bottle recycling of PET via nanostructure formation by melt intercalation in twin screw compounder: improved thermal, barrier, and microbiological properties. J Appl Polym Sci 106:1375-1382. https://doi.org/10.1002/app.26730

[14] Ghasemi H, Carreau PJ, Kamal MR, Tabatabaei SH (2012) Properties of PET/Clay nanocomposite films. Polym Eng Sci 52:420-430. https://doi.org/10.1002/pen

[15] Al-abdulrazzak S, Jabarin SA (2002) Processing characteristics of poly (ethylene terephthalate): hydrolytic and thermal degradation. Polym Int 173:164-173. https://doi.org/10.100 2/pi.813

[16] Kruse M, Rolón-Garrido VH, Wagner MH (2013) Rheological characterization of degradation and polycondensation of poly(ethylene terephthalate) melt in air and in nitrogen. AIP Conf Proc 1526:216-229. https://doi.org/10.1063/1. 4802616

[17] Hayrapetyan S, Kelarakis A, Estevez L et al (2012) Nontoxic poly(ethylene terephthalate)/clay nanocomposites with enhanced barrier properties. Polymer 53:422-426. https://d oi.org/10.1016/j.polymer.2011.12.017

[18] Frounchi M, Dourbash A (2009) Oxygen barrier properties of poly(ethylene terephthalate) nanocomposite films. Macromol Mater Eng 294:68-74. https://doi.org/10.1002/ma me. 200800238

[19] Wang Y, Jabarin SA (2013) Novel preparation method for enhancing nanoparticle dispersion and barrier properties of poly(ethylene terephthalate) and poly(m-xylylene adipamide). J Appl Polym Sci 129:1455-1465. https://doi.org/ 10.1002/app.38853

[20] Majdzadeh-Ardakani K, Zekriardehani S, Coleman MR, Jabarin SA (2017) A novel approach to improve the barrier 
properties of PET/clay nanocomposites. Int J Polym Sci 2017:1-10. https://doi.org/10.1155/2017/7625906

[21] Gorrasi G, Senatore V, Vigliotta G et al (2014) PET-halloysite nanotubes composites for packaging application: preparation, characterization and analysis of physical properties. Eur Polym J 61:145-156. https://doi.org/10.1016/j.e urpolymj.2014.10.004

[22] Zid S, Zinet M, Espuche E (2018) Modeling diffusion mass transport in multiphase polymer systems for gas barrier applications: a review. J Polym Sci Part B Polym Phys 56:621-639. https://doi.org/10.1002/polb.24574

[23] Yuan P, Southon PD, Liu Z et al (2008) Functionalization of halloysite clay nanotubes by grafting with $\gamma$-aminopropyltriethoxysilane. J Phys Chem C 112:15742-15751. https://d oi.org/10.1021/jp805657t

[24] Sun P, Liu G, Lv D et al (2015) Effective activation of halloysite nanotubes by piranha solution for amine modification via silane coupling chemistry. RSC Adv 5:52916-52925. https://doi.org/10.1039/c5ra04444h

[25] Joussein E, Petit S, Churchman J et al (2005) Halloysite clay minerals: a review. Clay Miner 40:383-426. https://doi.org/ 10.1180/0009855054040180

[26] Vilarrasa-García E, Cecilia JA, Santos SML et al (2014) CO2adsorption on APTES functionalized mesocellular foams obtained from mesoporous silicas. Microporous Mesoporous Mater 187:125-134. https://doi.org/10.1016/j. micromeso.2013.12.023

[27] Yuan P, Tan D, Annabi-Bergaya F et al (2013) Changes in structure, morphology, porosity, and surface activity of mesoporous halloysite nanotubes under heating. Respir Care 58:561-573. https://doi.org/10.1346/CCMN.2012.0600602

[28] Cheng R, Li H, Liu Z, Du C (2018) Halloysite nanotubes as an effective and recyclable adsorbent for removal of lowconcentration antibiotics ciprofloxacin. Minerals. https://doi. org $/ 10.3390 / \min 8090387$

[29] Wang B, Huang HX (2013) Effects of halloysite nanotube orientation on crystallization and thermal stability of polypropylene nanocomposites. Polym Degrad Stab 98:1601-1608. https://doi.org/10.1016/j.polymdegradstab.2 013.06 .022

[30] Raji M, Mekhzoum MEM, Rodrigue D et al (2018) Effect of silane functionalization on properties of polypropylene/clay nanocomposites. Compos Part B Eng 146:106-115. https://d oi.org/10.1016/j.compositesb.2018.04.013

[31] Tan D, Yuan P, Annabi-bergaya F et al (2013) Natural halloysite nanotubes as mesoporous carriers for the loading of ibuprofen. Microporous Mesoporous Mater 179:89-98. htt ps://doi.org/10.1016/j.micromeso.2013.05.007

[32] Kohyama N, Fukushima K, Fukami A (1978) Observation of the hydrated form of tubular halloysite by an electron microscope equipped with an environmental cell. Clays Clay Miner 26:25-40

Publisher's Note Springer Nature remains neutral with regard to jurisdictional claims in published maps and institutional affiliations. 